\title{
Bidding wind energy under uncertainty
}

\author{
Julio Usaola *, Jorge Angarita * \\ * Departamento de Ingeniería Eléctrica \\ Universidad Carlos III de Madrid \\ Av. Universidad 30. 28911 Leganés (Madrid). Spain
}

\begin{abstract}
The integration of wind energy into electricity markets implies that the wind energy must commit their production for a given time period. This requires the use of short term wind power prediction tools to prepare the bids for the spot market. The output of these tools have a limited accuracy, and, therefore, these predictions are uncertain. Optimal bids must take into account this uncertainty in order to get the maximum revenue from the sell of energy, minimizing losses due to imbalance costs. The consequence is that the optimal bids sent to the market do not coincide with the best predictions. Regulatory authorities must consider if this situation is good for the system operation, and encourage TSOs to have their own prediction tools and have results independent of bidding strategies.
\end{abstract}

Index Terms - Market integration of wind energy, wind power bidding, short term wind power prediction, prediction uncertainty.

\section{INTRODUCTION}

The liberalization of the electricity markets is an ongoing process within the EU countries [1], although the degree of liberalization and the market rules of the different countries differ widely. Participation of renewables and, in particular, wind energy, in these electricity markets is encouraged by regulatory authorities in the UE [2], [3], in order to reduce distortion in the own market, and to increase the transparency of the support necessary to achieve the objectives fixed by the own UE [2].

Up to now, the wind generation participates significantly in the electricity markets only in a few countries. Among them, Spain allows and incentivates this participation [4]. The result of this regulation is that more than $8300 \mathrm{MW}$ of wind energy participated in the market in October 2005 for an installed power of about $9300 \mathrm{MW}$ in the Peninsular electric system by that time.

To participate in an electricity market implies to present bids and to commit the delivery of de agreed amount of energy in an given moment. If the actual delivered energy differs from the committed, other generators must also change their schedule in order to maintain the balance between generation and load. The cost of this re-scheduling must be paid by those that cause it. The undispatchable nature of the wind generation makes necessary, when participating in an

This work has been performed with data of the EU funded project ANEMOS (Contract ENK5-CT-2002-00665) and has been funded by the Spanish Ministry of Education project RENOMER (DPI200300862). electricity market, to assess the power that the wind farm will deliver in the next hours. This assessment requires short term wind power prediction programs.

Studies about market integration of wind energy have appeared in literature only recently. In [5], a strategy for wind producers to present bids under the NETA rules is presented. These rules allow the presentation of bids only a few hours before the operation time, making less necessary the prediction tools. Most of the countries, however, follows different rules. The paper [6] evaluates the revenues of Spanish wind farms under conditions somewhat different from present ones. In [7], a study using the rules of the Dutch electricity market is presented. Bids are presented once a day and not updated in subsequent markets. The paper [8] makes a general study using the Spanish rules under different assumptions, and presenting one bid for each day, with different anticipation times before operation. They do not use any actual prediction tool, but works with average accuracies. In the paper [9], an analysis of the benefits of the use of short term wind power prediction tool in an electricity market is presented.

The accuracy of short term wind power prediction programs have been quantified in [10] and [11]. The performance of these programs is better if the elapsed time between the prediction and the operation times is short. This is why the probability of updating the prediction in subsequent intraday markets is an opportunity for reducing the penalties. The best bid to be done in these markets depend on the price paid in them for the energy in relation with the imbalance cost and on the uncertainty of the prediction. This uncertainty follows a probability distribution that is asymmetric. If this is joined to the fact that the cost of the imbalances is different if the actual production is higher or lower than the committed power, the result is that the best bid to be done to these intraday markets is not the expected value of the wind production, but a rather different one. The information given by the wind farm owners to the Power Exchange or the System Operator is, hence, not reliable for these agents.

The aim of this paper is to demonstrate the assertion written above by showing the results of simulations with data of real wind farms in a market with rules similar, but not exactly the same, than the Spanish market.

The contents of the paper are as follows. Section II describes how wind power may participate in electricity markets. The uncertainty of short term wind power 
prediction are quantified in Section III. Section IV presents the formulation of the optimization problem. Section $\mathrm{V}$ gives the assumptions used and presents the data used to obtain the results presented in Section VI. Section VII concludes the paper.

\section{WIND ENERGY AND ELECTRICITY MARKETS}

When wind energy participates in an Electricity pool, the wind farm owners must present bids to the markets some hours before operation. The bids to the daily market are made between 12 and 36 hours before operation. The accuracy of short term wind power prediction programs is not very high, and big errors may be produced. This is why the intraday markets may be used for updating the commitment of the daily markets, using more recent and accurate predictions (between 4 and 8 hours before operation time) for trading energy necessary in order to maximize their revenue. Not all markets have this possibility, but in many of them the bids may be updated several times a day.

In general terms, the revenue $R$ for a given wind farm in a pool market may be generalized as:

$$
R=\sum_{t} P_{d, t} \cdot M P_{t}+\sum_{t} M P_{i, t}\left(P_{i, t}-P_{d, t}\right)+\text { imbalance }
$$

Where

$$
\text { imbalance }=\left\{\begin{array}{cc}
+M P_{t}^{\text {sell }}\left(P_{\text {gen }, t}-P_{\text {last }, t}\right) & P_{\text {gen }, t}>P_{i, t} \\
-M P_{t}^{\text {buy }}\left(P_{i, t}-P_{\text {gen }, t}\right) & P_{\text {gen }, t}<P_{i, t}
\end{array}\right.
$$

The meaning of the different terms of the equations are:

$P_{g e n, t}$ Power actually generated by the wind farm in the hour $t$

$P_{d, t} \quad$ Power committed to the wind farm in the daily market for the hour $t$. It coincides with the prediction available at the gate closure of the daily market.

$P_{i, t}$ Power committed to the wind farm in the intraday market for the hour $t$ It coincides with the prediction available at the gate closure of the intraday market.

$P_{\text {last }, t}$ Power committed to the wind farm in the last update for the hour $t$

$M P_{t}$ Marginal price of energy in the daily market for the hour $t$

$M P_{i, t}$ Marginal price of energy in the intraday market for the hour $\mathrm{t}$

$M P_{t}^{\text {sell }}$ Marginal price of energy in the spot market for selling energy in the hour $t$

$M P_{t}^{\text {buy }}$ Marginal price of energy in the spot market for buying energy in the hour $t$

In the paper, the time sequence of the different markets are shown in Table 1, where ' $\mathrm{P}$ ' indicates the moment when the predictions are produced. In this figure, it is assumed that there is a daily market and six intraday markets that take place each four hours. It can be seen that the bids should be presented 13 hours before the beginning of the daily market, and 3 hours before the beginning of the intraday markets. This means that the predictions for the daily markets must have a time horizon between 13 and 36 hours, while the predictions for the intraday markets are produced between 3 and 6 hours before the operation time. The updating, then, means that the updated predictions are between 10 and 30 hours after the daily market prediction.



Figure 1. Time schedule of the different markets.

\section{SHORT TERM WIND POWER PREDICTION. UNCERTAINTY.}

The principles of short term wind power prediction may be found in many references. The program SIPREÓLICO, as a representative sample, is described in [12]. The accuracy of these tools may be also found in [11], for instance. This accuracy varies with each wind park, the level of the power and many other variables. The curve shown in Figure 1 (taken from [14]) may be representative of this accuracy.

\section{SIPREOLICO performance (week 52 2003)}

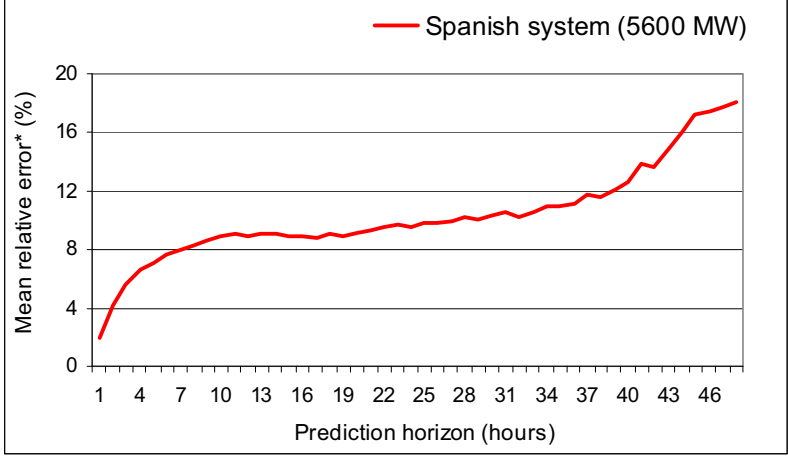

Figure 2. Performance of SIPREÓLICO

The uncertainty of this production have been less studied, although some studies may be found in and in for a parametric approach. This uncertainty, for each farm depends on the production level and the time horizon, among other factors. To obtain this uncertainty analytically is a complex task, specially if it is generated at the same time than the prediction, but an empirical approach may be done from past results.

The probability functions of the predictions are calculated by looking at the actual production of the wind farm when a prediction have been made, and calculating the frequency of these occurrences for a given power level and time horizon. By this way, the probability (or frequency) of producing the power $P_{\text {gen }}$ when the power predicted is $P_{\text {pred }}$ is calculated easily. These results may be assimilated to a standard distribution function. For instance, in [13], a Beta function is proposed. This parametric approach is currently a subject of research. 

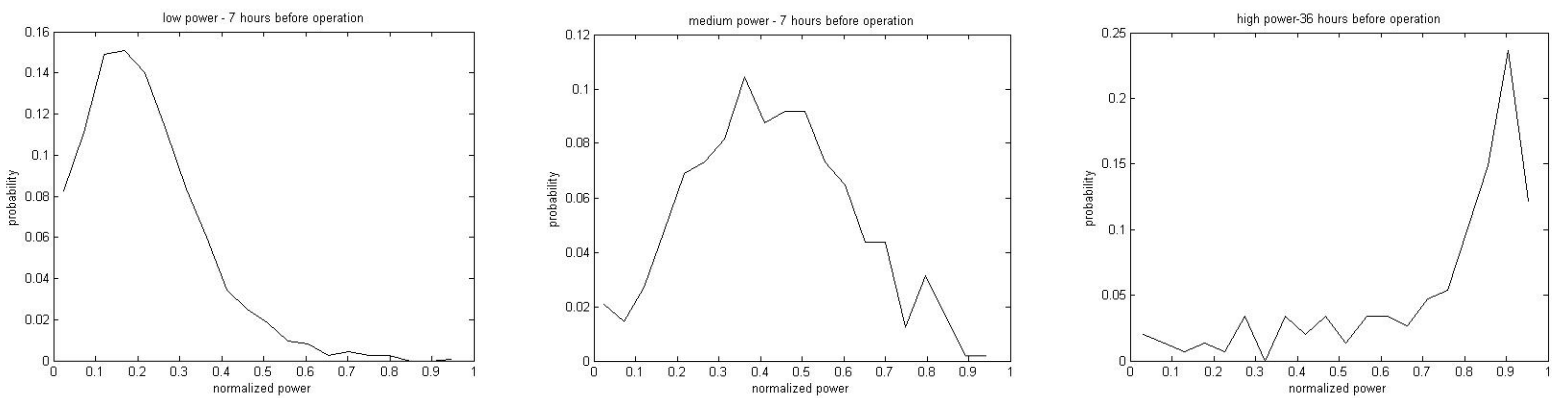

Figure 3. Frequency of the occurrences. From left to right, low power, medium power and high power distributions, 7 hours before the operation time. $\mathrm{X}$ axis is normalized to the rated power.

In this paper, the actual values of the obtained distribution have been obtained from past predictions for the same wind farm. Although a more refined approach could be made, it is not believed that this would yield very different results. Figure 3 shows the typical frequency distributions that can be obtained.

It can be observed that the shape of the function is different for different production levels and time horizons.

In general, the shape of the frequency distributions when the predicted power is low and when it is close to the rated power is similar to an exponential. However, when the predicted value is in the medium range of the wind farm, the probability density functions tend to be more like a Gaussian.

It can be also said that when the prediction is made more hours before, the probability density functions tend to be flatter.

\section{FORMULATION OF THE PROBLEM.}

The revenues of the wind farm are calculated using the formulas (1) and (2). In the intraday markets, the bid to the daily market (the committed power) is already known, as well as the price for the energy in this market. The price of the intraday markets are unknown, although they can be predicted, as well as the price of the imbalance. At the time of the intraday market, a prediction is generated for the next hours, and this prediction has an uncertainty estimated from past data as explained in last section. Then, the revenue for a given time could be expressed as a function of the power bid (or traded) in the intraday markets, and the power actually generated, as $R\left(\boldsymbol{P}_{\text {last }}, \boldsymbol{P}_{\text {gen }}\right)$, where $\boldsymbol{P}_{\text {last }}$, and $\boldsymbol{P}_{\text {gen }}$ are vectors of bid and generated powers for a whole period (one day, for instance).

The aim of the problem is to obtain the value of $\boldsymbol{P}_{\text {last }}$ that maximizes the revenue for a given set of intraday energy prices, imbalance costs and the uncertainty of the prediction. This problem may be formulated for each hour as in eq. (3). The formulation for more hours is straightforward. Since time couplings between the different hours are not considered, this formulation is general.

$$
\max _{P_{\text {last }}} \sum_{j=1}^{j=N}\left\{R\left(P_{\text {last }}, P_{\text {gen }, j}\right) \cdot \rho\left(P_{\text {gen }, j} \mid P_{\text {pred }}(\Delta t)\right)\right\}
$$

Where $N$ is the number of bins that have been considered in the uncertainty probability density function, $P_{\text {pred }}(\Delta t)$ is the prediction of the wind power, that was produced $\Delta t$ hours before the actual operation time, and $\rho\left(P_{\text {gen }, j} \mid P_{\text {pred }}(\Delta t)\right)$ is the probability of the generated power to take the value $P_{\text {gen }, j}$ when the prediction $\Delta t$ hours before has been $P_{\text {pred }}$.

The assumed hypothesis for the study have been the following:

- A pool system has been considered. Wind producers make their bids for a given amount of power at price zero. This means that bids are always accepted.

- The prediction of the prices of the intraday market are perfect.

- The subsidies for wind energy are not considered.

- The prediction tool makes new prediction from available data (wind forecasts and real-time production) every hour.

- SIPREÓLICO has been the prediction tool used for performing the prediction. The performance of this program may be considered as representative, as shown in the comparative study [10]. Information about SIPREÓLICO may be found in [12].

\section{STUDY CASE}

The data of wind farm come from the actual production of a wind farm of $14 \mathrm{MW}$ of rated power during three months. The probability functions of the wind farm have been obtained from these same production data and predictions performed for this wind farm for these three months.

Although the study conditions do not follow the Spanish market rules, the prices of the Spanish market between January and March 2003 have been used for this study. The level of the prices is given in Figure 4. The average price for this period was $23.678 \mathrm{r}$ c $€ / \mathrm{MWh}$. The intraday market prices for this period where also used. The average intraday market price used was 22.4791 c€/MWh. 


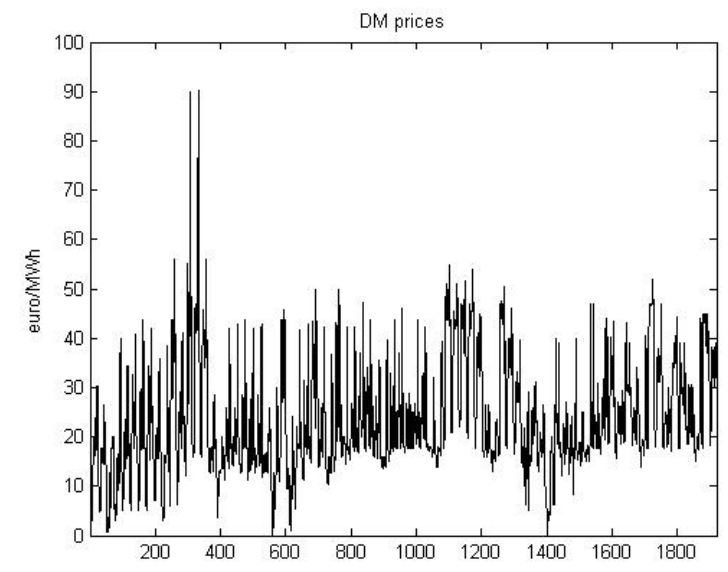

Figure 4. Prices for the period considered.

The study performed includes a comparison between three different assumptions:

1. OPTIMAL: The described method of maximizing the revenues taking into account the uncertainties of the wind power prediction tool.

2. BEST PREDICTION: When the best prediction available is used to modify the bid in the intraday markets.

3. NO INTRADAY: When no updating is produced in the intraday market. Therefore, only one bid per day is produced.

The study has been performed for eighty days. Longer studies, however, do not lead to very different results.

\section{Results}

For the three assumptions, and for values of $M P^{\text {sell }}=$ $0,5 \cdot M P$ and $M P^{b u y}=1,5 \cdot M P$, the revenues, the average errors and the average of the absolute value of the errors along the whole period are presented in Table 2. It can be seen there that the most profitable option presents larger errors than the most accurate. Errors and absolute errors for instant $t$ are defined as:

$$
\begin{aligned}
& \text { error }_{t}=P_{\text {last }, t}-P_{\text {gen }, t} \\
& \text { abs_err } t_{t}=\left|P_{\text {last }, t}-P_{\text {gen }, t}\right|
\end{aligned}
$$

TABLE I

\begin{tabular}{|l|c|c|c|}
\hline \multicolumn{1}{|c|}{ ERRORS FOR THE DIFFERENT ASSUMPTIONS } \\
\hline OPTIMAL & $\begin{array}{c}\text { BEST } \\
\text { PREDICTION }\end{array}$ & $\begin{array}{c}\text { NO } \\
\text { INTRADAY }\end{array}$ \\
\hline Revenues $(€)$ & 290112 & 280500 & 269046 \\
\hline Error $(\mathrm{MW})$ & -0.3661 & 0.1412 & 0.1619 \\
\hline $\begin{array}{l}\text { Absolute } \\
\text { error(MW) }\end{array}$ & 1.8722 & 1.4132 & 2.0198 \\
\hline
\end{tabular}

The values of $M P^{\text {sell }}$ and $M P^{b u y}$ are realistic in the sense that, usually, to buy energy at the last moment is more expensive than to sell it. Real systems, however, have slightly more complex methods to calculate the cost of the imbalances.

Figure 5 shows the differences between the three cases. The asterisks $(*)$ show the difference between the OPTIMAL and the BEST PREDICTION assumptions. The diamonds show the difference between the OPTIMAL and the NO INTRADAY assumptions. The dotted line shows the difference between the BEST PREDICTION and the NO INTRADAY assumptions. It may be observed that the difference, especially between OPTIMAL and BEST PREDICTION is almost always greater than zero. Only in some cases where the predictions had been bad, the results for the BEST PREDICTION were better than the OPTIMAL assumptions.

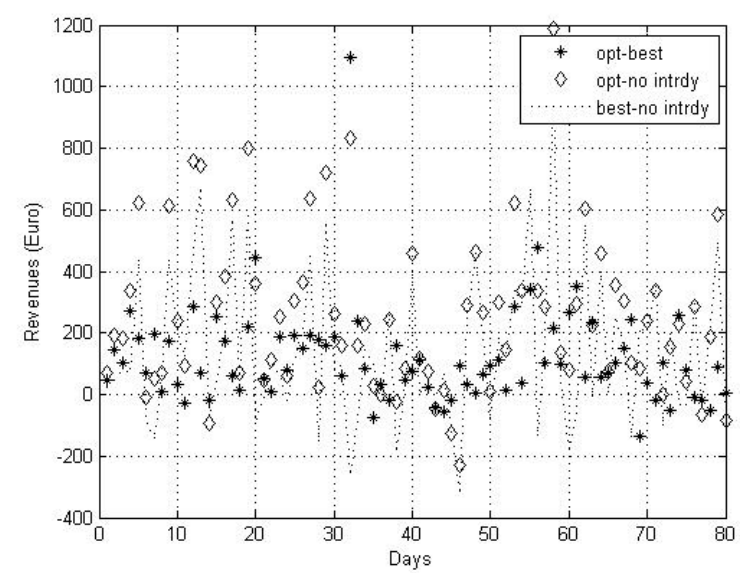

Figure 5. Results for one month of the cases studied.

However, if we check the error between the actual generated power and the different powers, as shown in Table I, we can see that, even if the errors of the OPTIMAL assumptions are greater, the revenues obtained are higher, and then, the bids provided by the wind farm owners aiming to maximize their revenues are not the most accurate. In Figure 6 a sample of the power error in a series of 30 hours is shown. It may be seen there, that the error of the best prediction is higher than the optimal, and that this one is lower than if only bids to the intraday markets are presented. Although there are cases where this does not happen, the general behavior follows this pattern.

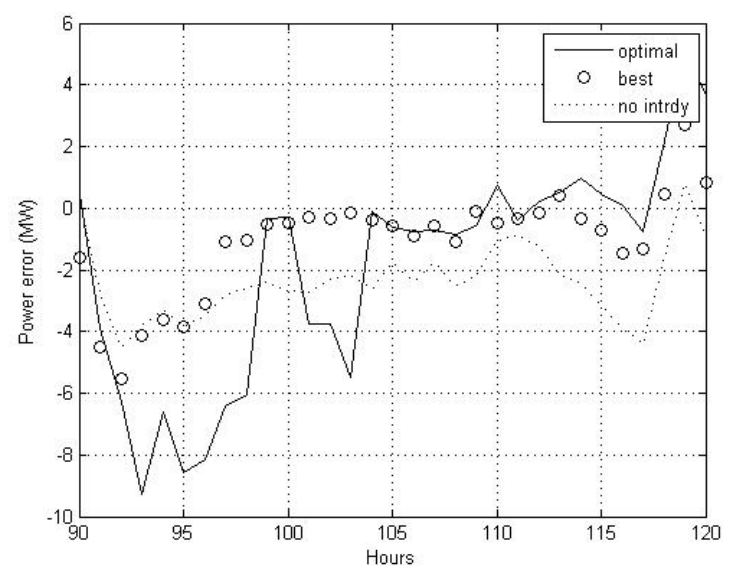

Figure 6. Power errors for a series of 30 hours. 
From Table I we can deduce that the prediction tool has a trend for overprediction, because the errors, defined as in (4) are positive. This is more apparent when the buy and sell prices change from those assumed in the previous results. Although the following discussion is mainly of theoretical interest, it gives a good insight into the properties of the process.

The Table II gives different results for different values of sell and buy prices. The second column has the same values as the first row of Table I, for an easier comparison.

TABLE II

REVENUES FOR DIFFERENT SELL AND BUY PRICES $(€)$

\begin{tabular}{|l|c|c|c|}
\hline Buy/Sell prices & $1.5 / 0.5$ & $1 / 1$ & $0.5 / 1.5$ \\
\hline Optimal & 290112 & 348834 & 467178 \\
\hline Best prediction & 280500 & 311751 & 343002 \\
\hline No intraday & 269046 & 313039 & 357032 \\
\hline
\end{tabular}

We can see in this table that:

1. The revenue when bidding the optimal power is always the highest of the three possible bids.

2. The revenue is higher when the sell price becomes greater. This means that the system tends to overpredict, and then, power must be bought at the last moment most of the times.

3. When the sell price is equal or lower than the buy price, the revenues are larger when no updates are made in the intraday markets. This is also a consequence of the tendency to overpredict, since the error is higher in this last case, as shown in Table I.

In order to show the bias of the errors and absolute errors, these errors are given in Tables III and IV. In them, the values for the BEST PREDICTION and NO INTRADAY assumptions given in Table I are also included for an easier comparison.

TABLE III

AVERAGE ERRORS FOR DIFFERENT SELL AND BUY PRICES (MW)

\begin{tabular}{|l|c|c|c|}
\hline Buy/Sell prices & $1.5 / 0.5$ & $1 / 1$ & $0.5 / 1.5$ \\
\hline Optimal & -0.3661 & $-0,2423$ & 0,6255 \\
\hline Best prediction & \multicolumn{3}{|c|}{0,1412} \\
\hline No intraday & \multicolumn{3}{|c|}{0,1619} \\
\hline
\end{tabular}

TABLE IV

AVERAGE ABSOLUTE ERRORS FOR DIFFERENT SELL AND BUY PRICES (MW)

\begin{tabular}{|l|c|c|c|}
\hline Buy/Sell prices & $1.5 / 0.5$ & $1 / 1$ & $0.5 / 1.5$ \\
\hline Optimal & 1.8722 & 4.2822 & 5.5945 \\
\hline Best prediction & \multicolumn{3}{|c|}{1.4132} \\
\hline No intraday & 2.0198 \\
\hline
\end{tabular}

From these tables we may conclude also that:

- The lowest errors are always given by the BEST PREDICTION case. This better performance, however, does not lead to the highest revenues, even compared with the NO INTRADAY option.

- The errors from the OPTIMAL case show that with this strategy, the trend to overpredict of the prediction tool is compensated. When the sell price is higher than the buy price, the bid tends to be higher than the actual generation. The fact that the average error is negative when both prices are equal is another consequence of this trend to overprediction.

\section{CONCLUSIONS}

The main conclusions of the presented work could be summarized as follows:

1. A wind generator must use a short term wind power prediction program, if it must participate in the market, presenting bids for the next day.

2. The most accurate prediction is achieved when bids are updated in intraday markets, using more recent predictions.

3. The most accurate prediction, however, do not lead to the highest revenues. This is due to the different prices of spilled and bought energy and to the bias of the prediction programs.

4. In order to have a maximum revenue, the uncertainty of the power prediction must be considered. This leads to stochastic optimization, although not very complex.

5. The uncertainty is not easy to model, although from past predictions useful approaches can be made.

\section{REFERENCES}

[1] European Commission Directive 2003/54/EC of the European Parliament and of the council of 26 June 2003 concerning common rules for the internal market in electricity and repealing Directive 96/92/EC.

[2] European Commission Directive 2001/77/EC on the promotion of electricity produced from renewable energy sources in the internal electricity market.

[3] ETSO Report on renewable energy sources. Brussels, December 2003.

[4] Ministry of Economy RD 436/2004, Methodology for payment of the Special Regime.

[5] G.N Bathurst, G. Strbac "Trading Wind Generation in Short Term Energy Markets" IEEE Trans on Power Systems. Vol. 17-3, 2002.

[6] J. Usaola, et al. "Benefits for wind energy in electricity markets from using short term wind power prediction tools; a simulation study". Wind Engineering. Vol. 28 no. 1, 2004.

[7] P. Pinson, C. Chevalier, G. Kariniotakis "Optimizing benefits from wind power participation in electricity markets using advanced tools for wind power forecasting and uncertainty assessment". Proc. of EWEC 2004. London 2004.

[8] A. Fabbri, T. Gómez, J. Rivier, V. Méndez "Assessment of the Cost Associated With Wind Generation Prediction Errors in a Liberalized Electricity Market". IEEE Trans on Power Systems. Vol. 20-3, 2005. 
[9] J. Usaola, J. Angarita "Benefits of short term wind power prediction programs for the integration of wind energy in electricity markets.". EWEC 2006. Athens 2006.

[10]G. Kariniotakis et al. "What performance can be expected by short term wind power prediction models depending on site characteristics?". Proc. of EWEC 2004. London 2004.

[11] G. Kariniotakis et al. "Evaluation of Advanced Wind Power Forecasting Models -Results of the Anemos Project". EWEC 2006. Athens 2006.

[12]I. Sánchez, "Short-term prediction of wind energy production", Int. J. Forecasting, vol. 22, no. 1, pp. 43-56.

[13] S. Bofinger, A. Luig, and H. G. Beyer, "Qualification of wind power forecasts", Proc. Global Wind Power Conf., Paris, France, April 2-5, 2002.

[14] G. González, B. Díaz-Guerra. F. Soto, S. López, I. Sánchez, J. Usaola, M. Alonso, M.G. Lobo, "SIPREÓLICO-Wind Power Prediction Tool for the Spanish Peninsular Power System", 2004 CIGRE 40th General Session \& Exhibition., Paris, France, August 2004. 